\section{Fetal gender and maternal serum screening markers}

To the Editor:

Although results from several studies have suggested that fetal gender may have an effect on the maternal serum concentration of pregnancy-related products, ${ }^{1-8}$ we could not find a controlled study in which clinical confounding variables that may affect the concentration of maternal serum screening markers for chromosomal and pregnancy complications had been excluded from analysis before the evaluation of the possible effect of fetal gender. For this reason, we performed a nested study in which the clinical records of 213 pregnant women who had consented to donate blood for biochemical research purposes during pregnancy were reviewed in a proto-

Nested study in which a chart review was conducted after delivery on patients that had donated blood for research in pregnancy

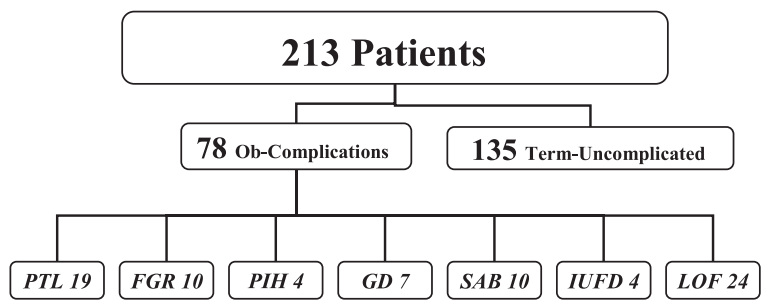

Fig. 1. This was a nested study in which the clinical records of 213 pregnant women who had consented to donate blood for biochemical research purposes during pregnancy were reviewed. Ob, obstetric; PTL, preterm labor $(<37$ completed weeks); FGR, fetal growth restriction; $\mathrm{PIH}$, pregnancy-induced hypertension; GD, gestational diabetes; $\mathrm{SAB}$, spontaneous abortion; IUFD, intrauterine fetal demise; LOF, loss of follow-up. col approved by the institutional review board of Texas Tech University. Gestational age at maternal blood sampling and estimated date of delivery were calculated in all pregnancies using ultrasound measurements as documented in the medical records. Figure 1 summarizes the study design and clinical classification of patients. Sixty-two percent of patients were white, 29\% were Hispanic, 4\% were African American, and 5\% were of other cultural backgrounds. For the purpose of this study, the maternal serum samples from the 135 patients with uncomplicated singleton pregnancies that resulted in term deliveries of appropriately grown neonates without congenital anomalies were thawed and used to measure the concentration of the five maternal serum analytes. Of these 135 patients, 123 had donated blood during the first trimester of pregnancy at a mean gestational age of 11.9 weeks ( standard deviation $=1.5$ ), and 129 had donated blood during the second trimester at a mean gestational age of 16.8 weeks ( standard deviation $=1.3$ ). First-trimester serum samples (10-14 weeks) were analyzed for free $\beta$-human chorionic gonadotropin and pregnancy-associated placental protein-A by enzyme-linked immunosorbent assay. Second-trimester serum samples (15-20 weeks) were analyzed for alpha-fetoprotein and human chorionic gonadotropin by enzyme-linked immunosorbent assay and for unconjugated estriol by second antibody radioimmunoassay. All assays were from Diagnostic Systems Laboratories, Inc. (Webster, TX). Intraassay coefficients of variation averaged less than $5 \%$, and interassay coefficients of variation were between $7 \%$ and $11 \%$. All samples were analyzed in duplicate. Clinical and maternal serum biochemical data were entered into the Statistical Package for the Social Sciences (SPSS Inc.,

\section{Female}

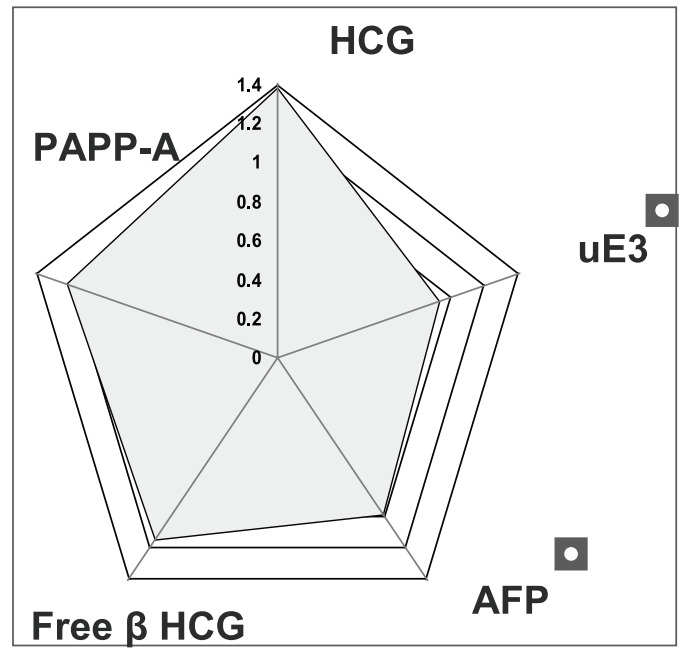

$p<0.05$
Male

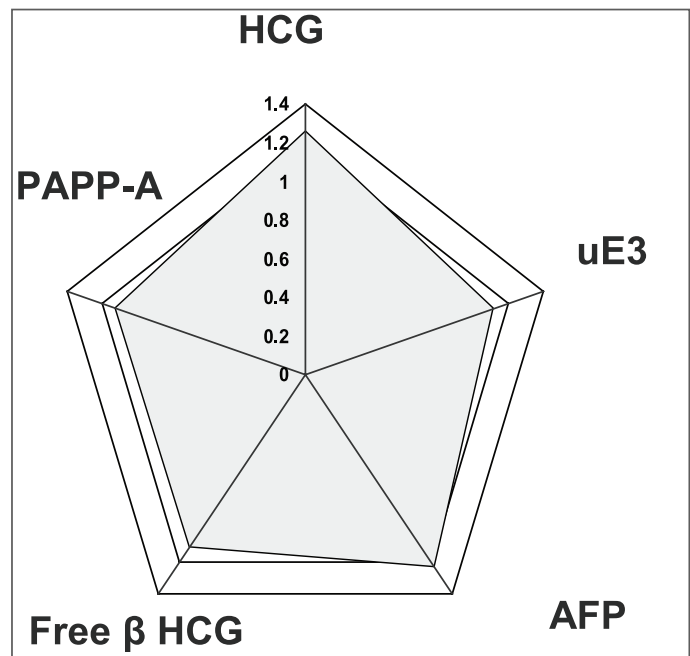

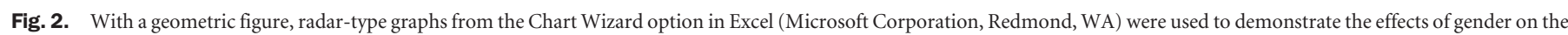

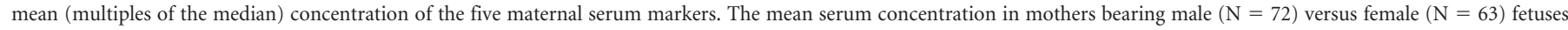

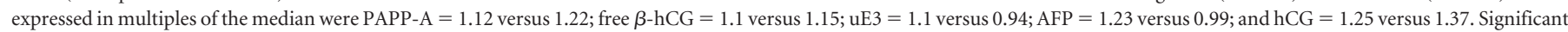

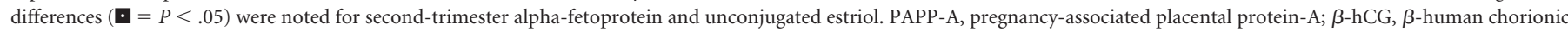
gonadotropin; $\mathrm{uE3}$, unconjugated estriol; AFP, alpha-fetoprotein. 
Chicago, IL), and summary statistics were calculated. Biochemical data were stratified by gestational age at the time of maternal blood sampling and expressed as multiples of the median for the week interval. Multiples of the median were then entered into Excel (Microsoft Corporation, Redmond, WA) in rows with males and females in separate columns. Analysis of variance was used to determine group differences. The significance level was set at $P$ less than .05 . No differences in maternal age, time of blood donations, gestational age at delivery, newborn weights, or 5-minute Apgar scores were observed between women bearing male versus female fetuses. Graphic depictions of the mean concentration of the five analytes classified by fetal gender are shown in Figure 2. These findings suggest that mothers bearing female fetuses may have lower alpha-fetoprotein and unconjugated estriol serum concentrations. In addition, our data concur with previous studies reporting higher $\beta$-human chorionic gonadotropin and human chorionic gonadotropin concentration in mothers bearing female fetuses.

\author{
Joaquin Santolaya-Forgas, $\mathrm{MD}, \mathrm{PhD}^{1}$ \\ Michael Mahoney, $\mathrm{MD}^{2}$ \\ Mazen Abdallah, $M^{2}$ \\ Jose Duncan, $M D^{2}$ \\ Alberto Delgado, $\mathrm{MD}^{2}$ \\ Perkin Stang, $M D^{2}$
}

Juan DeLeon, $\mathrm{MD}, \mathrm{PhD}^{3}$ V. Daniel Castracane, $\mathrm{PhD}^{4}$

From the ${ }^{1}$ Departments of Obstetrics and Gynecology at Brigham and Women's Hospital, Boston, Massachusetts; ${ }^{2}$ Wayne State University, Detroit, Michigan; ${ }^{3}$ Texas Tech University Health Science Center, Amarillo, Texas; and ${ }^{4}$ Foundation for Blood Research, Scarborough, Maine.

\section{References}

1. Crosignani PG, Nencioni T, Brambati B. Concentration of chorionic gonadotrophin and chorionic somatomammotropin in maternal serum, amniotic fluid and cord blood serum at term. J Obstet Gynaecol Br Commonw 1972;(79):122-126.

2. Ghidini A, Spong CY, Grier RE, Walker CN, et al. Is maternal serum triple screening a better predictor of Down syndrome in female than in male fetuses? Prenat Diagn 1998;(18):123-126.

3. Lockwood CJ, Lynch L, Ghidini A, Lapinski R, et al. The effect of fetal gender on the prediction of Down syndrome by means of maternal serum alpha-fetoprotein and ultrasonographic parameters. Am J Obstet Gynecol 1993;(169):1190-1197.

4. Santolaya-Forgas J, Meyer WJ, Burton BK, Scommegna A. Altered newborn gender distribution in patients with low mid-trimester maternal serum human chorionic gonadotropin (MShCG). J Matern Fetal Med 1997;(6):111-114.

5. Spencer K, Ong CY, Liao AW, Papademetriou D, et al. The influence of fetal sex in screening for trisomy 21 by fetal nuchal translucency, maternal serum free beta-hCG and PAPP-A at 10-14 weeks of gestation. Prenat Diagn 2000;(20):673-675.

6. Steier JA, Myking OL, Bergsjo PB. Correlation between fetal sex and human chorionic gonadotropin in peripheral maternal blood and amniotic fluid in second and third trimester normal pregnancies. Acta Obstet Gynecol Scand 1999;(78):367-371.

7. Yaron Y, Lehavi O, Orr-Urtreger A, Gull I, et al. Maternal serum HCG is higher in the presence of a female fetus as early as week 3 post-fertilization. Hum Reprod 2002; (17): 485-489.

8. Yaron Y, Wolman I, Kupferminc MJ, Ochshorn Y, et al. Effect of fetal gender on first trimester markers and on Down syndrome screening. Prenat Diagn 2001;(21):10271030 . 